Aleksandra Milovanović

Univerzitet Umetnosti

Fakultet dramskih umetnosti u Beogradu
316.774:004.9

https://doi.org/10.18485/climb.2017.5.2.ch8

\title{
AUDIO-VIZUELNE ARHIVE: METOD, MODEL, MEDIJI ${ }^{1}$
}

\section{Sažetak}

Cilj ovog rada je da ispita modele formiranja audio-vizuelnih digitalnih arhiva, njihove mogućnosti i prednosti, ali i kompleksne probleme i ograničenja sa kojim se ove arhive suočavaju. Istraživanje će biti okrenuto načinima formiranja novih digitalnih arhiva koje proširuju naše shvatanje arhiva i medija, zbog toga što su prvi put u istoriji različite vrste zapisa i formata (slika, zvuk, pisani dokumenat, itd.) dostupni u jednom mediju za arhiviranje, pretraživanje i analiziranje (CD-rom, DVD, digitalne baze podataka, virtualni muzeji, digitalne biblioteke, itd.). Ali, dok jedne studije postavljaju pitanje da li nas to uvodi u mračno vreme medijatizacije sećanja, dominacije sveprisutne prošlosti i sećanja prema zahtevu (memory on demand), druge pozitivno gledaju na bezgranične mogućnosti e-sećanja, e-istorije, e-arhive, e-znanja, e-učenja.

Ključne reči: audio-vizuelni arhivi, digitalizacija, e-sećanje, novi mediji

Proces digitalizacije audio-vizuelnih arhivskih materijala postao je ključan izvor informacija o prošlosti, jer uz štampana dokumenta, knjige i prikaze, ovi materijali (arhivski snimci - profesionalni i amaterski, fotografije, video-svedočenja, dokumentarni filmovi i serije, itd.) jesu vredan prilog i izvor za tumačenje kulture, društva, politike i istorije. Smatra se da „audio-vizuelni dokumenti su dela koja sadrže sliku i/ili zvuk na nosaču koji je moguće reprodukovati i čije: snimanje, prenos, percepcija i razumevanje obično zahteva tehnički uređaj; vizuelni i/ili zvučni sadržaj koji ima linearno trajanje“ (Edmondson 2016, 27). Rej Edmundson (Ray Edmondson) u UNESCO-voj studiji o principima audio-vizuelnog arhiviranja razdvaja i

$1 \quad$ Ovaj rad je deo projekta Identitet i sećanje: transkulturalni tekstovi dramskih umetnosti i medija, (projekat br. 178012), Fakulteta dramskih umetnosti u Beogradu. 
definiše dva osnovna pojma u proučavanju, smatrajući da se „audio-vizuelno odnosi na pokretne slike i/ili zvuke, snimljene na bilo kom mediju (nosaču), uključujući ali ne ograničavajući se na film, traku ili disk ili bilo koji drugi medij koji je sada poznat ili još nije izmišljen“ (Edmondson 2016, 28), dok za arhiv, kao instituciju koja brine o očuvanju audio-vizulenih materijala, smatra da je „samostalna organizacija deo veće organizacije čiji zadatak je prikupljanje, upravljanje, čuvanje i obezbeđivanje pristupa ili korišćenja zbirke audio-vizuelnih i srodnih materijala. Izraz obuhvata vladine, nevladine, komercijalne i kulturne organizacije koje se bave ovim funkcijama." (Edmondson 2016, 28).

Arhivi, muzeji, biblioteke i audio-vizuelni arhivi pod uticajem su iste tradicije i istorije i imaju dosta zajedničkog, jer koriste slične discipline kojima prikupljaju građu, konzerviraju materijale iz zbirke, kao i slične metode i strategije da organizuju i obezbede pristup kolekcijama. Ali, ako ih posmatramo kao institucije u klasičnoj tradiciji, njihove razlike su očigledne. Međutim, proces digitalizacije najčešće ih izjednačava sa audio-vizuelnim arhivama zbog istih/sličnih strategija vizuelne prezentacije u novim medijima. Terminološki, u nekim zemljama se za audio-vizuelne arhive koriste reči za biblioteku (bibliothèque, biblioteca), te se stoga i cinemathèque (cinemateca, sinematek, kinemathek) upotrebljava za filmski arhiv, phonothèque ili discoteca za zvučni arhiv, médiathèque za audio-vizuelnu arhivu. Po istom principu, reč muzej (museum) se upotrebljava u određenom broju arhiva². Audio-vizuelna arhiva ponekad može biti označena kao kolekcija (collection), što naglašava podređenost većoj organizaciji ili instituci$\mathrm{ji}^{3}$. Prezervacija audio-vizuelnih materijala obuhvata brojne procese, principe olakšice i aktivnosti: očuvanje i restauraciju nosača, rekonstrukciju oštećenih delova, kopiranje i procesiranje vizuelnog i/ili zvučnog sadržaja, digitalizaciju radi stvaranja duplikata zarad lakšeg pristupa ili očuvanja,

2 Na primer, u Evropi postoji nekoliko filmskih muzeja (film museums). U nekim, ali ne u svim, slučajevima naglašena je određena kolekcija ili prikaz predmeta i ostalih artefakata kao što su kostimi, rekviziti ili tehnička oprema koja se nekada koristila

3 Neke od najpoznatijih audio-vizuelnih arhiva su Francuska kinoteka (Cinémathèque Française), Ina (Institut national de l'audiovisuel), Austrijski fonografski muzej (Osterreichishes Phonogrammarchiv), Ruska kinoteka (Госфильмофонд), američki MBRS (Library of Congress: Motion Picture, Broadcasting and Recorded Sound Division), Arhiv Volta Diznija (Walt Disney Archives), Muzej Džordža Istmana (George Eastman Museum/ Motion Picture Department), Institut Smistonijon (Smithsonian Institution), Jevrejski filmski arhiv Stivena Spilberga (Steven Spielberg Jewish Film Archive), itd. 
održavanje nosača unutar posebnih prostora za skladištenje, obnavljanje zastarelih tehničkih procesa i opreme, istraživanje i prikupljanje informacija da bi se obavile sve navedene radnje.

Formiranje digitalnih audio-vizuelnih arhiva podrazumeva tradicionalne principe upravljanja, ali i nove paradigme i metode koji proizlaze iz same prirode audio-vizuelnih medija i njihovog prelaska u digitalni registar. Teoretičari, ali i brojne organizacije odgovorne za audio-vizuelno nasledstvo, istražujući pitanja digitalnih audio-vizuelnih arhiva, smataju da je za njihovo formiranje $s$ jedne strane potreban interdisciplinarni pristup istorije, filozofije, kulture i umetnosti, dok je sa druge strane razvoj audio-vizuelnih arhiva usko povezan sa novomedijskim praksama i razvojem tehnologije. Takođe, digitalni formati jednostavno ne zamenjuju analogne, već isti arhivi nakon digitalizacije audio-vizuelnog zapisa ili dokumenta štite i čuvaju oba, zbog čega je ovo područje postalo veoma kompleksno. Zabluda je da pravljenje digitalne kopije sa ugroženog nosača ujedno podrazumeva kraj priče, a zapravo je samo početak, jer je očuvanje audio-vizuelnih materijala kontinuiran i beskonačan zadatak u odnosu na sve novije medije koji se pojavljuju. Zbog toga proces čuvanja (preservation) audio-vizuelnih materijala treba posmatrati kroz odnos metod - model - mediji, a ne samo kao digitalno remastrovanje (digitally remastered) za DVD ili internet i običnu promenu formata (od analognog u digitalni).

Da nove tehnologije i zaštita kulturnog nasleđa nisu nespojive kategorije potvrđuje stručna publikacija grupe autora: Preporuke za stvaranje i upravljanje digitalnom foto-dokumentacijom u institucijama zaštite kulturnog nasleđa Srbije (2015) u kojoj se daju preporuke za formiranje audiovizuelnih arhiva, sa posebnim osvrtom na fotografiju, a u ovom radu biće izloženi opšti principi njihovih preporuka. Unapređenje formiranja, rada i vizuelne prezentacije audio-vizuelnih arhiva jedan je od „najznačajnijih segmenata u zaštiti kulturnog nasleđa, od čije organizovanosti, pravilne usmerenosti i metodološke doslednosti zavisi kvalitet budućih intervencija u zaštiti nasleđa" (Polić 2015, 6). Autori kroz analizu potreba institucija zaduženih za zaštitu i očuvanje kulturnih dobara Srbije daju neophodne osnove za utvrđivanje standarda za upravljanje digitalnim arhivama jer se i u svetskim okvirima preporučuje da „muzeji, zavodi, arhive i biblioteke uspostave takozvani sistem za upravljanje digitalnim elementima (Digital 
Asset Management System - DAMS) koji obuhvata digitalnu arhivu (fotografije, audio i video snimke, tekstualne podatke itd.) i tako olakša njeno korišćenje u skladu sa politikom rada, potrebama i praksom svake institucije“ (Aćimović 2015, 103). Najzad, upravljanje digitalnim arhivama podrazumeva i poznavanje zakona i zakonskih akata koji pokrivaju širok spektar delatnosti, od obaveza institucija za zaštitu kulturnog nasleđa do pitanja autorstva i autorskih prava.

Prilikom stvaranja sistema za upravljanje audio-vizuelnim arhivama neophodno je definisati ciljeve i potrebe: inventarisanja nasleđa, konzervacije i restauracije; istraživanja nasleđa; angažovanih stručnjaka; zainteresovane stručne, javnosti; edukacija publike; prezentacija nasleđa - publikacije, izložbe, zastupljenost na internetu. Veća dostupnost korisnicima iz domena stručne i naučne javnosti, kao i široke javnosti, cilj je svake institucije koja se bavi nasleđem, zbog čega je potrebno „da svaka institucija razvija i unapređuje dostupnost kao proces, kako fizičku dostupnost svojih zbirki svim korisnicima, tako i intelektualnu dostupnost" (Stijović $2015,115)$. Direktna (neposredna) dostupnost foto-dokumentacije podrazumeva direktni kontakt korisnika sa dokumentacijom preko osoblja institucije. Indirektna (posredna) dostupnost foto-dokumentacije vrši se elektronskim putem i zavisi od opremljenosti institucije informacionim tehnologijama, programima i merama zaštite. Korisnici mogu biti: interni (kustosi, naučnici, muzejski stručnjaci i saradnici), eksterni (profesori, studenti, doktorandi, istraživači, novinari, pisci, likovni kritičar) i široka javnost (publika, ljubitelji umetnosti, kolekcionari, sponzori, turisti). Jednostavnost u proceduri, izostanak vremenskog i prostornog ograničenja, dostupnost velikom broju koristnika, čak i u isto vreme, (najčešće) besplatno korišćenje, mogućnost zloupotrebe svedena na minimum i zaštita foto-dokumentacije prednosti su posredne dostupnosti foto-dokumentacije. Ona se obavlja preko interneta, veb-sajta institucije, društvenih

4 „Sastavni deo upravljanja dokumentacijom, i njenog čuvanja, jeste briga o mogućnosti zastarevanja i širenja formata (korišćenje više različitih verzija jednog formata), što za posledicu može da ima nekompatibilnost opreme, programa i postojeće digitalne dokumentacije." (Aćimović 2015, 109). Pored fizičkog uništenja, veliku opasnost za očuvanje digitalne dokumentacije predstavlja i zastarelost formata skladištenja. Zato je uz garanciju proizvođača neophodno imati i ustanovljen protokol „za proveru stanja opreme i formata, izradu rezervnih kopija" (Aćimović 2015, 109), analizu rizika i, za svaki slučaj, plan reagovanja u vanrednim situacijama. 
mreža, aplikacija. Indirektni pristup ipak zahteva zaštitu od zloupotreba i obavezno vođenje računa o autorskim pravima.

U oblasti konzervacije nasleđa, na početku ovog milenijuma došlo je do novih trendova i strategija, te ova oblast više ne predstavlja akumulaciju standardnih informacija i podataka, već kompleksan i višeslojan pristup kojim se unapređuje „funkcija arhiva, koji umesto tradicionalne, evidenciono-memorijalne funkcije, dobijaju novu, aktivnu kulturnu misiju“ (Polić 2016, 9). U fokusu Evropske komisije (European Commission) i Kreativne Evrope (Creative Europe) za podršku i unapređenje kulturnog baštinjenja i očuvanja nasleđa najvećim delom su strategije koje se odnose na digitalizaciju oblasti: konzervacije, digitalizacije i unapređenja infrastrukture. Jedna od njihovih najvećih ostvarenih projekata do sada je Evropeana (Europeana) koji sadrži internet bazu sa pristupom 2.500 evropskih muzeja, biblioteka i arhiva. Ova baza funkcioniše po principu otvorenog pristupa (Open Access). U okviru Evropeaninog projekta o Prvom svetskom ratu (First World War Collections, European Film Gateway, EFG 1914-1918) Jugoslovenska kinoteka učestvuje kroz likove za digitalno restaurirane verzije reportaža Đoke Bogranovića i film Golgota Srbije: požar na Balkanu (Stanislav Krakov 1930, 1940).

Digitalizacijom i arhiviranjem svih vrsta meterijala i formata oni postaju dostupni za široku cirkulaciju, ali su digitalne arhive suočene sa dijalektikom koja je postojala u svim drugim istorijskim modelima arhiva: objekivno/subjektivno, očuvanje/propadanje, inkluzija/izostavljanje, autentičnost/falsifikat, transparentnost/cenzura, pamćenje/zaboravljanje. Sam tehnološki proces digitalizacije i postavljanja na internet ne obezbeđuje korisnicima interakciju kolektivnim pamćenjem i sećanjem. Stoga, treba naglasiti da se digitalni zapis i digitalna remedijacija odnose na dva različita procesa, što nas dalje upućuje na važnost kontekstualizacije digitalnog zapisa. Još jedno od važnih pitanja je metodologija primenjena u izboru i selekciji, odnosno šta će biti izostavljeno, a šta zastupljeno u arhivi. Ono što digi-arhivama nedostaje jeste standardizacija modela za formiranje arhiva i sistema za njihovu evaluaciju - šta su kriterijumi po kojima jednu digitalnu arhivu smatramo validnom.

Jasna vizuelna prezentacija, višejezična dostupnost i 24/7 dostupnost za sve vrste korisnika (ustanove kulture, udruženja, organizacije, istaživače, umetnike, eksperte, zaiteresovanu javsnost, itd.), preduslov 
su za dugoročne strategije razvoja transnacionalnih audio-vizuelnih arhiva, kao i digitalnog očuvanja kulturnog nasleđa5 ${ }^{5}$ Za sada, digitalne audiovizuelne arhive $u$ odnosu na svoje istorijske prethodnike imaju prednost jer su geopolitički dostupne u svakom trenutku, oslanjaju se na inovativne trendove imerzivnog/(inter)aktivnog participiranja i funkcionišu kao korisnička virtualna zajednica (Wolk 2015, Lotz 2017). Arhiv se više ne posmatra kao „udaljen repozitorijum (the out-of-the-way repository)" (Pinchevski 2011, 255) u kojem su procesi prikupljanja i selekcija kontrolisani mehanizmima neke institucije, muzeja ili arhiva. Digitalne multimedijalne arhive dostupne su na mreži u svakom trenutku za svakog ko je zainteresovan, predstavljajući nam prošlost kao „kontinurani tok vizueIne sadašnjosti (a permanent stream of visual present)" (Van Dijck 2011, 402). Nevena Daković u knjizi Studije filma: ogledi o filmskim tekstovima sećanja (2014) naglašava da se sećanje ispisano u „novim medijima i na njihovim ekranima razlikuje od onog koje se odvija u tradicionalnim medijima” (Daković 2014, 9), tražeći „nove/stare reprezentacijske obrasce” (Daković 2014, 137), narativizacije i memorijalizacije kolektivnog i individualnog sećanja.

U digitalnim arhivama raličite vrste zapisa i formata (slika, zvuk, animacija, pisana dokumenta, itd.) dostupni su u jednom mediju „za arhiviranje, skladištenje, pretraživanje, indeksiranje, analiziranje" (Blanchette $2011,25)$. Audio-vizuelne, ali i sve druge vrste digitalnih arhiva, povezuju interdisciplinarno polje (medija, arhive, istorije, sećanja, itd.) u sponi između procesa digitalizacije, arhiviranja, kontekstualizacije metapodataka, interaktivnosti, hipertekstualnosti, interkonektivnosti, komunikacije i kolektivnog sećanja (Ernst 2006). Modeli za razvoj arhiva u novim medijima (koji su promenili naše shvatanje i arhiva i medija) evoluirali su od interaktivnog CD-roma i DVD-ja do današnjeg standarda - Interneta. U digitalnim arhivama „sećanje i tehnologija uporedo se razvijaju (memory and technology co-evolve)" (Hoskins 2009, 101), što dalje utiče na

Ministarstvo kulture Srbije i Matematički institut SANU u avgustu 2017. godine potpisali su sporazum o njihovom hitnom sprovođenju. Veća dostupnost i vidljivost kulturne baštine, u domaćim i inostranim okvirima, deo je procesa značajnijeg razvoja infrastrukture i kapaciteta ustanova kulture, ali i približavanja standardima digitalnih trendova evropskih arhivskih i muzeoloških praksi. Značajno za teoriju filma je što je, paralelno sa ovim naporima, dovršeno postavljanje digitalne platforme časopisa Filmske sveske (1968-1986) u saradnji FDU, FCS, Ministarstva kulture i MISANU. 
stvaranje metafora kao što su sećanje na zahtev (memory on demand), savršeno sećanje (prefect memory), nemogućnost zaboravljanja (disability to forget), "trajna sadašnjost na mreži (the continuous present of the World-Wide Web)" (Van Dijck 2011, 404), kao i koršćenje digitalnog prefiksa $e-e$-sećanje (e-memory), e-istorija ( $e$-history), e-čuvanje (e-storage), e-arhiva (e-archive), itd. Volfgang Ernst (Wolfgang Ernst) u knjizi Digitalno sećanje i arhiv (Digital Memory and the Archive, 2013) navodi da je u digitalnim arhivama "na mikrotemporalnom nivou, sećanje je u permanentnoj konverziji” (Ernest 2013, 97) jer transformiše prošlost u sadržaj koji je uvek dostupan u sadašnjosti, što za posledicu ima permanentno prevođenje prošlosti u aktivno dostupnu sadašnjost.

O dijalektičkom odnosu (savršenog) pamćenja (perfect remembering) i (neizbežnog) zaboravljanja (inevitable oblivion) Gordon Bel (Gordon Bell) i Džim Geml (Jim Gemmell) u studiji Totalni opoziv, kako će revoluacija e-sećeanja promeniti sve (Total Recall, How the E-memory Revolution Will Change Everything, 2009) i Viktor Mej-Šonberger (Viktor Mayer-Schonberger) u Obrisano, Prednosti zaboravljanja u digitalnom dobu (Delete, The Virtue of Forgetting in the Digital Age, 2009), pokazuju različite stavove. Objavljene $u$ istom trenutku, ove dve studije deo su dve suprotstavljene perspektive i dva međusobno ospravana trenda koja se odnose na shvatanje digitalnih arhiva kao posebnog istorijskog statusa digitalnih podataka čiji je zadatak trajno očuvanje i zaštita istorijskog sećanja i pamćenja i koji su za razliku od svih analognih formata otporni na propadanje tokom vremena i upotrebe. I dok se u studiji Totalni opoziv pozitivno gleda na digitalno sećanje i (r)evoluciju digitalnih arhiva, u studiji Obrisano postavlja se pitanje da li nas digitalne arhive uvode u mračno vreme dominacije omniprisutne prošlosti.

Na osnovu broja nitratnih filmova koje čuva, Jugoslovenska kinoteka u Beogradu nalazi se među vodećima u svetu6. Međutim, u procesu digitalizacije zaostaje za brojnim arhivama, muzejima i kolekcijama, kao što je holandsko Oko (EYE Filmmuseum), čiji institut svoje aktivnosti najviše posvećuje digitalizaciji i očuvanju filmova7. Profesorka Filmskog nasleđa i

6 Arhiv nitratnog filma Jugoslovenske kinoteke čuva oko 15.000 filmova snimljenih u prvoj polovini 20. veka.

$7 \quad$ Na internet stranici Oka (EYE Restorations online) postavljen je program koji posetiocima omogućava da i sami restauriraju i obnove oštećenu filmsku traku, a nakon prolaska kroz ovaj proces, oni mogu uporediti na koji način je isti materijal restauriran u Oku. 
digitalne filmske kulture (Film Heritage and Digital Film Culture) na Univerzitetu u Amsterdamu, Đovana Fosati (Giovana Fossatti) već dvadeset godina vodeća je ekspertkinja iz oblasti digitalne restauracije filmova i glavna kustoskinja u filmskom muzeju Oko. Autorkine najuticajnije publikacije iz ove oblasti, u kojima povezuje teoriju i praksu, jesu Od filmskog zrna do piksela, arhivski život filma u tranziciji (From Grain to Pixel, The Archival Life of Film in Transition 2009, 2011), čije treće dopunjeno izdanje je u pripremi (2018) i Fantazija kolora u ranom filmu (Fantasia of Color in Early Cinema, 2015), na kojoj je sarađivala sa Tomom Ganingom (Tom Gunning) i u kojoj se otkriva alternativna istorija filma čiji je osnovni kriterijum bogatstvo i kreativnost u ručnom nanošenju boje u ranom filmu. Fosati u svojim publikacijama najčešće pokreće pitanja: Šta je filmsko nasleđe danas? Koja je uloga filmskih arhiva? Kako razumeti analogni film u digitalnom okruženju? Film kao medij ima kontinuitet od 120 godina isprepletene kulture i tradicije, analogne i digitalne tehnologije, zbog čega je u mnogim teorijskim diskusijama analogno-digitalno postavljena opozicija neproduktivna jer se analogni film posmatra pojednostavljeno. Ova odrednica mnogo je više od svođenja na vrstu filmske trake, u odnosu na bogatsvo nasleđa analognog filma (nosača: nitratnog, acetonskog, celuloidnog; vrsta širine trake: $8,16 \mathrm{~mm}, 35 \mathrm{~mm}, 70 \mathrm{~mm}$; formata: standardni ekran, widescreen, sinemaskop; vrsta zvuka: optički, magnetni, mono, stereo, THS; boje: crno-belo, ručno bojenje, kolor, tehnikolor; itd.). Digitalna prezervacija i restauracija najvidljiviji su deo širokog polja koje obuhvata filmsko nasleđe (Milovanović 2015, 2016) jer se danas otvoraju opcije koje ranije u laboratorijskom procesu (arhivsko/mokro kopiranje - negativ, intermedijarni pozitiv, duble negativ) u toj meri nisu bile moguće. Za restauraciju kolor zvučnih filmova, na primer iz 50-ih godina, od presudne važnosti je perfektnost restauracije; međutim, Fosati smatra da je nekada poželjno da se na kopiji koja je digitalno obnovljena ipak vidi trag vremena, kao i da materijalni tragovi u nitratnim filmovima (filmsko zrno, prljavština, oštećenja, itd.) svedoče o vremenu i istoriji.

Đovana Fosati ističe da se filmsko nasleđe kao teorijska disciplina uspostavlja u poslednje tri decenije u radovima Ganinga, Godroa (Andre Gaudreault) i Elsesera (Thomas Elsaesser) ${ }^{8}$, i za proučavanje filmsk-

$8 \quad$ O važnosti filmskog nasleđa govore mnoge teorijske studije (Tom Gunning The Cinema of Attractions: Early Film, Its Spectator and the Avant-Garde, 1986; Andre Gaudreault Film 
og nasleđa navodi trajektoriju spomenik, dokument, događaj (monument, document, event). Ona povezuje Fukoovo (Michel Foucault) tumačenje spomenika i dokumenta ${ }^{9}$ sa aspektima filmskog događaja, pod kojima podrazumeva bolju vidljivost, permanentnu online dostupnost i novu zainteresovanost publike za gledanje filmova sa početka kinematografije, smatrajući ih važnim delom kulturnog nasleđa i sećanja. Ovo mišljene blisko je Volfgangu Ernstu (Wolfgang Ernst), koji, proučavajući digitalne arhive, uviđa da su u njima prvi put u istoriji raličite vrste zapisa i formata (slika, zvuk, pisani dokumenti, itd.) dostupne u jednom mediju za indeksiranje, arhiviranje i pretraživanje (Ernst 2013). Ali, premisa da su digitalni formati superiorni u odnosu na analogne zato što upotrebom i vremenom ne propadaju, pokazala se netačnom, jer zastarevanje hardvera i softvera predstavlja sistematsku opasnost za digitalne arhive, a samim tim i za digitalnu kulturu. Stoga zaštita filmova predstavlja kontinuirani proces, pošto trajno „ništa nije sačuvano (nothing has ever been preserved) - samo je očuvano (it is only being preserved)" (Edmondson 2016, v). Jedna od najvećih opasnosti sa kojima se suočavaju digitalne video-arhive jeste migracija sadržaja sa jedne medijske platforme na drugu da bi se izbeglo zastarevanje video-formata, rezolucije i kompresije. Na primer, digitalni formati DVD i Blu-ray danas su zastareli u odnosu na DSP ili 8K digitalnu sliku. Fosati zato zaključuje da će filmske digitalne arhive, kako filmovi u njima ne bi zastarevali i dalje propadali, morati kontinuirano da se prenose u sve novije i novije formate.

\section{Literatura}

Aćimović, Marija (2015) „Upravljanje foto-dokumentacijom“, u Suzana Polić (ur.) Preporuke za stvaranje i upravljanje digitalnom foto-dokumentacijom u institucijama zaštite kulturnog nasleđa Srbije, str. 103-105. Beograd: Centralni institut za konzervaciju.

Aćimović, Marija (2015) „Očuvanje dokumentacije“, u Suzana Polić (ur.) Preporuke za stvaranje $i$ upravljanje digitalnom foto-dokumentacijom u institucijama zaštite

and Attraction: From Kinematography to Cinema 2012; Thomas Elsaesser Digital Cinema: Delivery, Event, Time, 1998, Film History as Media Archaeology Tracking Digital Cinema, 2016).

9 Fuko u knjizi Arheologija znanja (1998) iznosi tezu: „Istorija, u svom tradicionalnom obliku, nastojala je da „upamti“ spomenike prošlosti, da ih preobrazi u dokumenta [...]. U našem vremenu istorija preobražava dokumenta u spomenike." (Fuko 1998: 11-12). 
kulturnog nasleđa Srbije, str. 109-112. Beograd: Centralni institut za konzervaciju. Bell, Gordon and Jim Gemmel. Total Recall: How the E-Memory Revolution will Change Everything. New York: Dutton, 2009.

Daković, Nevena (2014) Studije filma: ogledi o filmskim tekstovima sećanja, Beograd: FDU, Institut za pozorište, film, radio i televiziju.

„European Commission - Supporting cultural heritage“, na internet adresi http:// ec.europa.eu/culture/policy/culture-policies/cultural-heritage_en.htm pristupljeno 20.03.2018.

„Europeana Collections“, na internet adresi https://www.europeana.eu/portal/en pristupljeno 20.03.2018.

„Europeana 1914-1918“, na internet adresi https://www.europeana.eu/portal/en/collections/world-war-I pristupljeno 20.03.2018.

Edmondson, Ray (2016) Audiovisual Philosophy and Principles, Third Edition, UNESCO.

Ernst, Wolfgang, (2006) "Dis/continuities: Does the Archive Become Metaphorical in Multi-Media Space?" in Chun, Wendy Hui Kyong and Keenan, Thomas (eds.), New Media, Old Media: a History and Theory Reader. New York: Routledge, pp. 105123.

Ernst, Wolfgang, (2013) Digital Memory and the Archive, Minneapolis: University of Minnesota Press.

„First World War Collections, European Film Gateway/EFG 1914-1918“, na internet adresi http://www.europeanfilmgateway.eu/about_efg/EFG1914collections pristupljeno 20.03.2018.

Fossatti, Giovana (2011) From Grain to Pixel, The Archival Life of Film in Transition, Amsterdam: Amsterdam University Press.

Fossatti, Giovana (2017) "What is Film Heritage Today? Reflections and Practices Beyond the Digital Turn" in Nevena Dakoivić (ed.) Balkan Cinema on the Crossroads: From Nitrat to Digital, Book of Abstracts, Beograd: FDU.

Fuko, Mišel (1998) Arhelogija znanja, Beograd: Plato.

Fickers, Andreas (2012) "Towards A New Digital Historicism? Doing History In The Age Of Abundance", VIEW Journal of European Television History and Culture Vol. 1, No.1, pp. 19-26.

Garde-Hansen, Joanne, Hoskins, Andrew and Reading, Anna (eds.) (2009). Save As ... Digital Memories. Basingstoke: Palgrave Macmillan.

Hoskins, Andrew (2009) "Digital network memory" in Astrid Erll and Ann Rigney (eds.) Mediation, Remediation and the Dynamics of Cultural Memory, Berlin: de Gruyter, pp. 91-108.

Hoskins, Andrew (2011) The Mediatization of Memory: Media and the End of Collective Memory, Cambridge, MA: MIT Press.

Hoskins, Andrew (2011) "From connective to collective memory" in Neiger, M., Meyers, O. and Zandberg, E. (eds.) On Media Memory, Collective Memory in a New Media Age, Basingstoke: Palgrave Macmillan, pp. 278-287.

Lotz, Amanda (2017) Portals: A Treatise on Internet-Distributed Television, Michigan: University of Michigan Library. 
Култура и/или наука

Mayer-Schonberger, Viktor (2009) Delete, The Virtue of Forgetting in the Digital Age Princeton, NJ: Princeton University Press, 2009.

Milovanović, Aleksandra (2015) „Novi mediji i (ne)oficijalne arhive: Korisnici u interakciji sa nacionalnim kulturnim nasleđem", Zbornik radova Humanizam: kultura ili iluzija, Beograd: Filološki fakultet. str. 339-350.

Milovanović, Aleksandra (2016) "Digital Archives Against the Oblivion: Fama Collection Sarajevo" u N. Daković, M. Nikolić, Lj. Rogač Mijatović (ur.) Media archaeology: Memory, media and culture in the digital age, Beograd: FDU, str. 109-122.

Neiger, Motti, Meyers, Oren, and Zandberg, Eyal (2011) (eds.) On Media Memory, Collective Memory in a New Media Age, Basingstoke: Palgrave Macmillan.

Noe, Bobbie Collective Memory and the Moving Image Archive: The Changing Sites of Memory in Europe, University of Amsterdam, Master Thesis 2014.

Olick, Jeffrey K. (1999) “Collective Memory: The Two Cultures” in Sociological Theory Vol. 17, No. 3., pp. 333-348.

Pennebaker, James (2013) Collective memory of political events, Social psychological perspectives, New Jersey: Psychology Press.

Pinchevski, Amit (2011) "Archive, Media, Trauma" in Neiger, Motti, Meyers, Oren, and Zandberg, Eyal (Eds.) On Media Memory, Collective Memory in a New Media Age, Basingstoke: Palgrave Macmillan, pp. 253-264.

Polić, Suzana (2015) „Uvodna reč”, u Suzana Polić (ur.) Preporuke za stvaranje i upravljanje digitalnom foto-dokumentacijom u institucijama zaštite kulturnog nasleđa Srbije, str. 6-7. Beograd: Centralni institut za konzervaciju.

Polić, Suzana (2016) „Uvodna reč, U civilizacijskom hodu”, u Suzana Polić (ur.) Otvoreni pristup muzejskoj dokumentaciji u Srbiji: iskustva, izazovi i potencijali, str. 9-11. Beograd: Centralni institut za konzervaciju.

Reading, Anna (2011) "Memory and Digital Media: Six Dynamics of the Globital Memory Field" in Neiger, Motti, Meyers, Oren, and Zandberg, Eyal On Media Memory, Collective Memory in a New Media Age New York: Palgrave Macmillan.

Stijović, Milja (2015) „Dostupnost foto-dokumentacije“", u Suzana Polić (ur.) Preporuke za stvaranje i upravljanje digitalnom foto-dokumentacijom u institucijama zaštite kulturnog nasleđa Srbije, str. 115-118. Beograd: Centralni institut za konzervaciju.

Sturken, Marita (2008) "Memory, consumerism and media: Reflections on the emergence of the field". Memory Studies 1(1), pp. 73-78.

Van Dijck, José (2007) Mediated Memories in the Digital Age. Stanford: Stanford University Press.

Van Dijck, José (2011) "Flickr and the culture of connectivity: sharing views, experiences, memories" Memory Studies 4 (4), pp. 401-415.

Verbruggen, Erwin, Oomen, Johan and Muller (2014) "Bringing Europe's Audiovisual Heritage Online: EUScreenXL", Iasa journal no 42, pp. 54-60.

Wolk, Alan (2015) Over The Top: How The Internet Is (Slowly But Surely) Changing The Television Industry, New York: CreateSpace Independent Publishing Platform. 


\author{
Aleksandra Milovanović \\ University of Arts \\ Faculty of Dramatic Arts, Belgrade
}

\title{
AUDIO-VISUAL ARCHIVES: METHOD, MODEL, MEDIA
}

\section{Summary}

The aim of this paper is to investigate possible models of construction of digital audio-visual archives, their development and advantages, as well as possible problems and constrains. This paper will investigate process of digitalization of audio-visual archival materials (archive footage - professional and amateur, photographs, video testimonies, documentary movies and series, etc.), which, as the source of memories and information about the past, alongside with wide range of print documents, books and press articles, provide access to understanding culture, society, history and overall past. Forming new media archives changed our understanding of both the archive and the media, because for the first time in history, different types of records (images, sounds, written documents, animation, etc.) are available in single media for storage, transmission and visualization (CD-rom, DVD, digital databases, virtual museums, digital libraries, etc.). New media studies offer different standpoints by drawing attention on the dangers of perpetual dark age dominated by an omnipresent past and memory on demand, and at the same time addressing the positive side of e-memory, e-history, e-archives, e-knowledge, e-learning. 